Article

\title{
Study on the Progressive Failure Characteristics of Longmaxi Shale under Uniaxial Compression Conditions by X-ray Micro-Computed Tomography
}

\author{
Xiao Li ${ }^{1,2}$, Yongting Duan ${ }^{1,2, *}$, Shouding $\mathrm{Li}^{1,2}$ and Runqing Zhou ${ }^{1}$ \\ 1 Key Laboratory of Shale Gas and Geoengineering, Institute of Geology and Geophysics, \\ Chinese Academy of Sciences, Beijing 100029, China; lixiao@mail.iggcas.ac.cn (X.L.); \\ lsdlyh@mail.iggcas.ac.cn (S.L.); r.zhou@mail.iggcas.ac.cn (R.Z.) \\ 2 College of Earth Science, University of Chinese Academy of Sciences, Beijing 100049, China \\ * Correspondence: ytduan@mail.iggcas.ac.cn; Tel.: +86-10-8299-8053
}

Academic Editor: Ranjith Pathegama Gamage

Received: 12 January 2017; Accepted: 28 February 2017; Published: 3 March 2017

\begin{abstract}
To investigate the deformation-failure process of Longmaxi shale under uniaxial compression conditions from the mesoscopic and macroscopic points of view, novel X-ray micro-Computed Tomography (micro-CT) equipment combined with unique loading apparatus was used. Cylindrical shale samples (4 $\mathrm{mm}$ in diameter and $8 \mathrm{~mm}$ in height) were produced to perform a series of uniaxial compression tests. CT scanning images at different time points during the loading process were obtained to study the characteristics of the progressive failure. In addition, stereograms were reconstructed and vertical slices were selected to explain the failure mechanism. From the results of the testing the low-density area, local per-peak cracks, numerous post-peak cracks and secondary cracks consecutively appeared in the CT images. Vertical and inclined fissures in the samples could be observed from the stereograms' surfaces and from internal slices. The cracking indicates that the failure process of shale is progressive and the failure mechanism of shale under uniaxial compression is mainly tension destruction or comprehensive tension-shear destruction.
\end{abstract}

Keywords: shale; X-ray micro-CT; uniaxial compression; progressive failure; destruction mechanism

\section{Introduction}

Shale gas is one of the most promising unconventional natural gas resources, with huge reserves located around the world [1]. It has been widely recognized that shale gas will play a large role in meeting future worldwide energy demands and become a significant part of the energy policy mix of many countries [2-4]. Owing to the geological characteristics of shale in gas reservoirs that generally show low penetrability and remarkable brittleness, large-scale hydraulic fracturing treatments are usually essential in the development of shale gas [5-7]. However, the efficiency of the fracturing technology is mainly dependent on a clear understanding of rock mechanical properties. Thus, it is necessary to know about the failure process and the fracture mechanism of shale, which contributes to guiding the fracturing engineering.

Experimental methods are the most important ways to study the rock properties and rock failure mechanisms [8]. So far, scholars have conducted a series of experiments to interpret the shale failure process. Patricia et al. [9], Dewhurst et al. [10] and Yan et al. [11] investigated the ultrasonic velocity response of shale under different stress conditions and evaluated the impact of stress anisotropy on the dynamic elastic properties of the shale. Amann et al. [12] and Qiao et al. [13] utilized acoustic emission (AE) measurements to study the clay shale under uniaxial compression tests and concluded that quantified stress levels are associated with the crack propagation patterns. Niandou et al. [14] and 
Li et al. [15] carried out comparison tests of four different kinds of shale under triaxial compression and observed splitting, shear and splitting-shear mixed failure modes under different confining pressures. Jia et al. [16], Hou et al. [17] and Zhang et al. [18] investigated Longmaxi shale under uniaxial compression and observed three failure modes associated with the bedding angles. Ma et al. [19] and Zou et al. [20] used micro-CT and a scanning electron microscope (SEM) to analyze the results of true triaxial fracturing experiments and explained the failure mechanism of shale by observing the geometrical morphology and structure of the fracture.

Experimental methods for understanding the progressive process of rock failure can be classified into three categories. The first category is an inverse problem from the physical properties of rocks, such as the P-wave velocity and the AE events. However, this is an indirect method for explaining the failure mechanism by analyzing the evolution of physical parameters. The second category is a surface process to observe the geometrical morphology of cracks by means of optical instruments. However, the internal failure mechanism only can be conjecture, owing to the surface cracking phenomena. The third category is a scanning process with special equipment such as X-ray CT. While the fractured rocks are observed using $\mathrm{CT}$ after failure occurred, the failure process and mechanism also depend on the conjecture of failed samples. Because of these problems, it is necessary to use in-situ X-ray tomography [21] to fully understand the mechanism of deformation. Although this method has been applied in the experimental researches of some rocks [22-27], it has not been carried out to study the progressive deformation-failure process of compact shale due to the limitation of X-ray scanning energy and loading apparatus capacity.

A novel X-ray micro-CT combined with the special loading apparatus was used to conduct the uniaxial compression tests of Longmaxi shale for the first time. The scanning experiments were carried out under loading conditions and the development of internal cracks under uniaxial loading stress could be directly observed, instead of being open to conjecture. The progressive failure characteristics of shale specimens under uniaxial loading process were obtained. Those results make important contributions to the understanding of shale failure mechanism, and guide fracturing engineering towards discovering more unconventional energy sources.

\section{Experimental Set-Ups and Methods}

\subsection{The Tested Materials}

The shale samples for this experiment were obtained from the outcrop of Longmaxi formation in Sichuan Basin, China. The values of quartz content and other brittle minerals (such as plagioclase, potassium feldspar, calcite, dolomite and pyrite) within Longmaxi shale was 55.5\% and $72.94 \%$, respectively [28]. Cylindrical samples were cored from the same block of shale to analyze the mechanical response. In order to keep the shale sample from weathering, it was sealed by plastic film and wax. There were no obvious cracks in the shale block with horizontal bedding. The relation between the drilling direction and the bedding is shown in Figure 1. Five experimental specimens with a diameter of $4 \mathrm{~mm}$ and a height of $8 \mathrm{~mm}$ were made using a hand-operated electric drill with a diamond coring bit. The top and the bottom of those specimens were then smoothed to achieve parallel surfaces for testing using a cutting-grinding machine, which had a precision of $60 \mu \mathrm{m}$. Table 1 shows the basic physical and mechanical parameters of Longmaxi shale. 

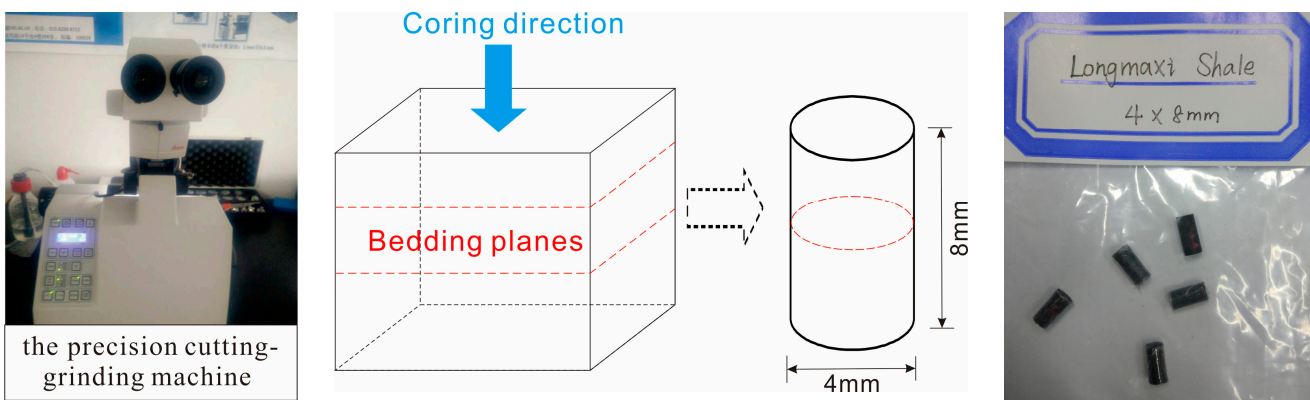

Figure 1. Directional coring diagram of specimen and the final specimens.

Table 1. Basic physical and mechanical parameters of the made shale samples.

\begin{tabular}{|c|c|c|c|c|c|c|c|}
\hline $\begin{array}{l}\text { Sample } \\
\text { Number }\end{array}$ & $\begin{array}{c}\text { Mass } \\
(\mathrm{g})\end{array}$ & $\begin{array}{l}\text { Height } \\
(\mathrm{mm})\end{array}$ & $\begin{array}{l}\text { Diameter } \\
(\mathrm{mm})\end{array}$ & $\begin{array}{l}\text { Height/Diameter } \\
\text { Ratio }\end{array}$ & $\begin{array}{l}\text { Density } \\
\left(\mathrm{g} / \mathrm{cm}^{3}\right)\end{array}$ & $\begin{array}{l}\text { Uniaxial Compression } \\
\text { Strength (MPa) }\end{array}$ & $\begin{array}{c}\text { Elasticity } \\
\text { Modulus (GPa) }\end{array}$ \\
\hline Sample 1 & 0.26 & 8.347 & 4.007 & 2.08 & 2.470 & 93.102 & 10.38 \\
\hline Sample 2 & 0.24 & 8.030 & 4.050 & 1.98 & 2.320 & 75.301 & 4.19 \\
\hline Sample 4 & 0.25 & 7.935 & 4.017 & 1.98 & 2.486 & 100.104 & 6.62 \\
\hline Sample 5 & 0.26 & 8.584 & 4.022 & 2.13 & 2.384 & \multicolumn{2}{|c|}{ standby sample } \\
\hline
\end{tabular}

\subsection{Experimental Equipment}

The experiments in this study were carried out on the uniaxial loading device integrated with the X-ray micro-CT in the Institute of Geology and Geophysics, Chinese Academy of Science, Beijing, China. The X-ray micro-CT device used here comprises three main parts: X-ray source, the rotated table and the detector (Figure 2). The energy of the $\mathrm{X}$-ray source can range from 30 to $160 \mathrm{kV}$, from which high resolution CT images can be obtained. The rotary table was designed to record the radiographies of a specimen at different angular positions as it rotates and reconstructs the external and internal geometries of the specimen. The detector used a two-stage magnification principle to achieve higher resolution (unique spatial resolution of $<50 \mathrm{~nm}$ ), this process is different from the conventional X-ray CT. Figure 3 shows the schematic diagrams of the difference between them. In this study, cone beam $\mathrm{X}$-ray was used for scanning, and its energy reached $90 \mathrm{kV}$ in voltage and $88.9 \mu \mathrm{A}$ in current. The voxel size is $11.27 \times 11.27 \times 8 \mu^{3}$ by combining the high energy of $X$-ray with the unique detector, which is sufficient to observe the internal cracks during the failure process of shale.

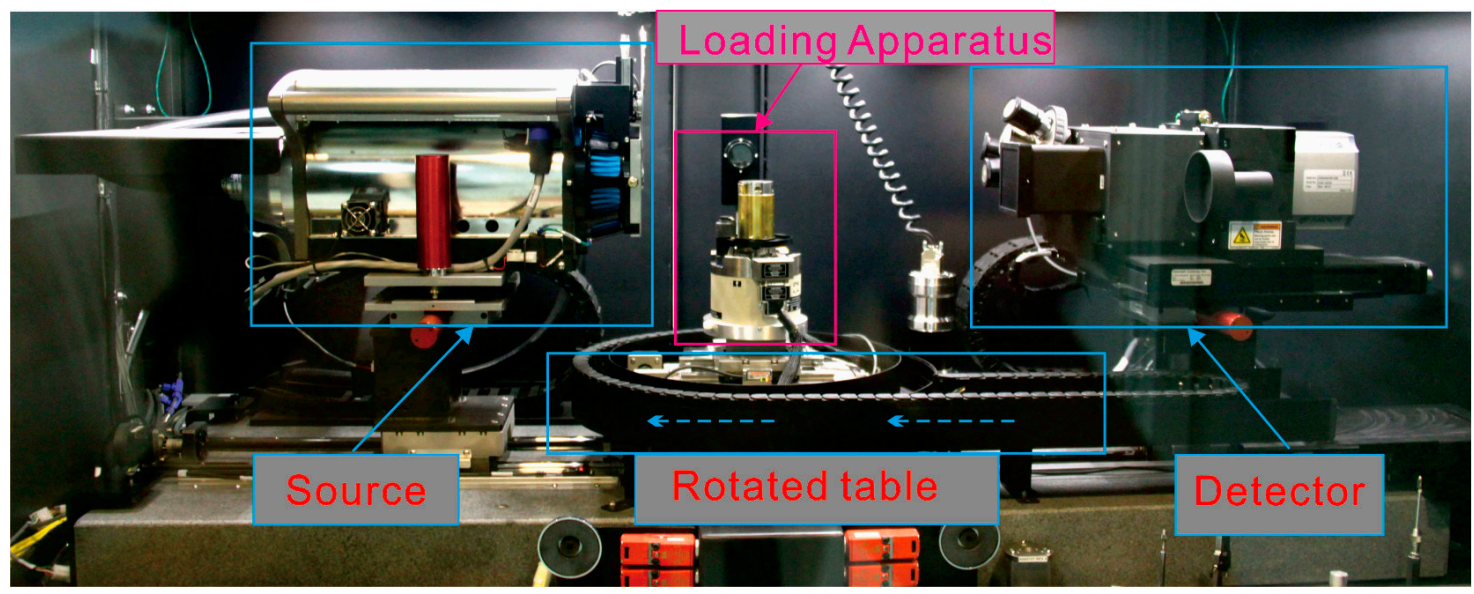

Figure 2. The overview of the experimental equipment. 


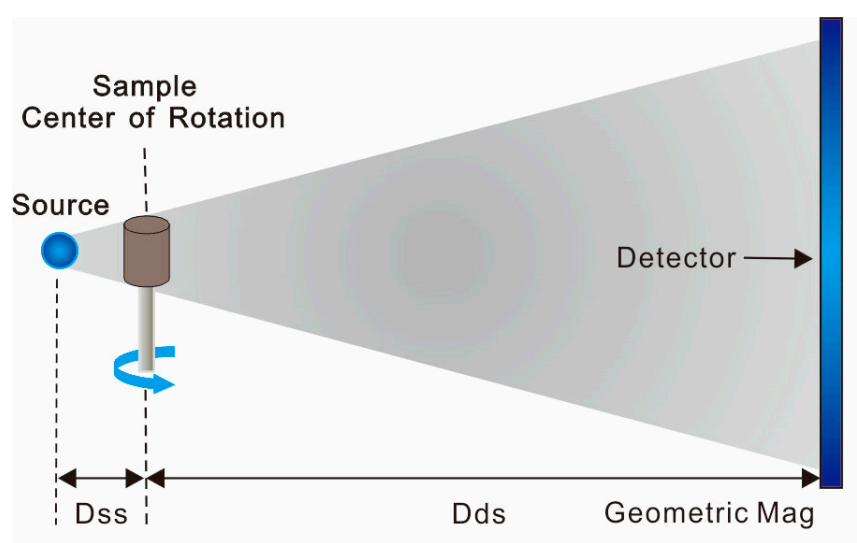

(a)

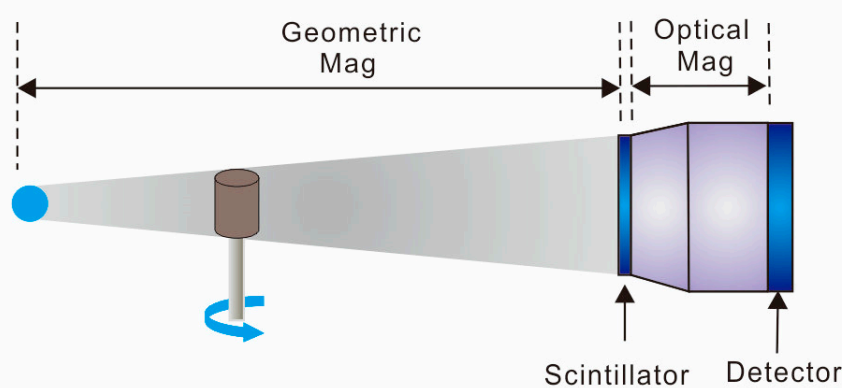

(b)

Figure 3. Schematic diagrams of the difference between the conventional X-ray CT and the X-ray micro-CT: (a) the conventional X-ray CT; (b) the X-ray micro-CT in this test. (Dss means the distance between the $\mathrm{X}$-ray source and the scanning sample, Dds means the distance between the detector and the scanning sample.)

The loading device was specifically designed for a CT scanner with a rigid frame, which is generally similar to the conventional testing system except for its much smaller size and a confining cell that is transparent to the $\mathrm{X}$-ray. This loading system has a maximum loading capacity of $5 \mathrm{kN}$ (equivalent to a stress of $398 \mathrm{MPa}$ for a sample of $4 \mathrm{~mm}$ diameter). The constant displacement rate can be adjusted in the range of $0.03-3 \mathrm{~mm} / \mathrm{min}$. This loading apparatus was placed on the rotary table of the X-ray micro-CT for scanning during the uniaxial loading process. In this study, the loading was performed under a minimal constant displacement rate of $0.03 \mathrm{~mm} / \mathrm{min}$ in order to get more information during the loading process. This loading rate corresponds to a nominal axial strain rate of $6.25 \times 10^{-5} \mathrm{~s}^{-1}$ for a specimen of $8 \mathrm{~mm}$ height.

\subsection{Experimental Procedures}

Four uniaxial compression tests were conducted by X-ray micro-CT equipment. Coupling agents were used on both ends of the cylindrical samples to reduce the end friction effect. The displacement rate remained the same during the loading process but temporary pauses were required for $\mathrm{CT}$ scanning, in order to obtain the progressive failure characteristics of the shale, and to determine the right moment (when loading was stopped to conduct the CT scanning) for CT scanning during the whole process of deformation and failure. Uniaxial compression tests on samples 1 and 2 were firstly conducted to obtain the complete stress-strain relationship on the conventional uniaxial tests without CT scanning. Each test takes about seven minutes. Then the right moments for CT scanning during the loading process were determined based on those complete stress-strain relationships of samples 1 and 2 . Then the uniaxial compression tests on samples 3 and 4 were conducted with some temporary pauses at the right moments for CT scanning during the loading process. 
In order to get the progressive development of the cracking process at different levels of axial stress, samples 3 and 4 were both scanned at seven different steps, which is numbered from step 1 to step 7 . Because each scanning step takes about 40 minutes, such a test with seven scanning steps takes 3-4 hours. These different steps include an intact status at step 1 before the loading, five steps at different axial stress during the loading process and a failed status at step 7 after the loading. As shown in Table 2, the values of scanning stress and their ratios of the UCS (Uniaxial Compression Strength) for CT scanning are listed. Samples 3 and 4 were both scanned at four pre-peak steps and three post-peak steps during the testing (Figures $4 a$ and $5 a$ ). The numbers marked on the stress-strain relationships are the step numbers of the temporary pauses for CT scanning. It is worth noting that the specimen was scanned while the strain held constant, which unavoidably causes some amount of axial stress relaxation during scanning. However, this relaxation is relatively small in the view of the complete stress-strain relationship of samples 3 and 4 (Figures 4a and 5a) and can be ignored [29]. Additionally, in order to get the progressive failure characteristics of shale, the pauses during the loading process were necessary and the relaxation was unavoidable.

Table 2. Scanning stress and the ratios of UCS under in-situ tests.

\begin{tabular}{ccccccccc}
\hline \multicolumn{2}{c}{ Scanning Steps } & $\mathbf{1}$ & $\mathbf{2}$ & $\mathbf{3}$ & $\mathbf{4}$ & $\mathbf{5}$ & $\mathbf{6}$ & $\mathbf{7}$ \\
\hline \multirow{2}{*}{ Sample 3 } & Scanning stress & \multirow{2}{*}{0} & 19.68 & 59.59 & 80.61 & 10.22 & 10.22 & \multirow{2}{*}{ Ratios of UCS } \\
& & $23.64 \%$ & $71.6 \%$ & $96.85 \%$ & $12.28 \%$ & $12.28 \%$ & \\
\hline \multirow{2}{*}{ Sample 4 } & Scanning stress & \multirow{2}{*}{0} & 18.26 & 49.63 & 70.28 & 97.42 & 15.5 & \multirow{2}{*}{0} \\
& Ratios of UCS & & $18.23 \%$ & $49.55 \%$ & $70.16 \%$ & $97.26 \%$ & $15.48 \%$ & \\
\hline
\end{tabular}

\section{Selected Results}

\subsection{The Meso-Damage Cracks and the Macro Deformation}

Since X-ray micro-CT uses cone beam for scanning, 1000 horizontal 2-D images can be collected by the detector at each right time for CT scanning. Figures 4 and 5 show the experimental results of samples 3 and 4, respectively. Firstly, the complete stress-strain relationship and some corresponding $X$-ray tomography images were shown. Those images were from the same elevation $(6 \mathrm{~mm}$ from the bottom of the original specimen) in different scanning steps. Secondly, the evolution of partial CT images at different elevations $(6.0 \mathrm{~mm}, 5.8 \mathrm{~mm}, 5.6 \mathrm{~mm}, 4.8 \mathrm{~mm}, 4.0 \mathrm{~mm}$ and $3.2 \mathrm{~mm}$ from the bottom, respectively) throughout the test were selected.

As shown in Figures 4 and 5, the failure process of shale can be divided into six stages according to the change of the $\mathrm{CT}$ images and the stress-strain relationships during the uniaxial compression tests. The meso-damage evolution of cracks and the macro characteristics of deformation in each scanning stage are described as follows:

1. Initial compression stage, OA: Some low-density regions, as shown in the tomography sections at scanning step 1 of sample 3, disappear at step 2. This change is obvious at elevations between $5.8 \mathrm{~mm}$ and $6.0 \mathrm{~mm}$. It indicates that the original small pores and defects in the shale specimen were compacted. Concave-shape stress-strain relationships were caused by this irrecoverable deformation.

2. Linear elastic deformation stage, AB: Once the shale was compacted and low-density regions disappeared, linear elastic deformation takes place. Those CT images from scanning step 2 to step 3 do not show any major change. There are not any new cracks generated. The stress-strain curves exhibit a linear elastic relationship and occupy the main parts of the pre-peak curves.

3. Crack initiation and growth stage, BC: There are some small cracks (widths of $50 \mu \mathrm{m}$ in sample 3 and $30 \mu \mathrm{m}$ in sample 4 ) appearing at the edge of the CT images at scanning step 4 . Cracks occur in the upper portion of the samples and disappear at elevations between $5.6 \mathrm{~mm}$ and $4.8 \mathrm{~mm}$. 
The initiation and growth of cracks causes convex-shape curves after the stress exceeded the elastic limit.

4. Strain-softening stage, CD: A large number of cracks arise in all CT scanning results at scanning step 5. Some cracks penetrate throughout the samples to form the splitting or shearing fracture. This phenomenon is generated by macro failure and causes negative slope steep curves. The strain-softening stage is the most unstable stage during the loading process.

5. Residual deformation stage, DE: The number of cracks has no distinct change and the morphology of cracks remains almost the same from scanning step 5 to step 6 . The stress-strain curves tend to be horizontal and the value of the residual stress in our tests is 5-10 MPa.

6. Unloading stage, EF: Some secondary cracks are produced, but the phenomena of cracks closure still exist from scanning step 6 to step 7. Those changes are complex and indicate that unloading of the axial stress has a dual effect. The springback of the stress-strain curves shows that restorable elastic deformation still exists, although the rock specimens have been destroyed.

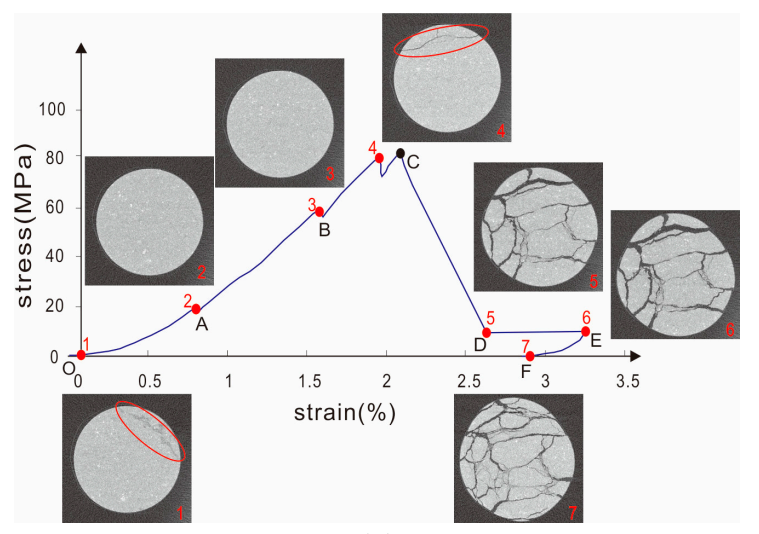

(a)

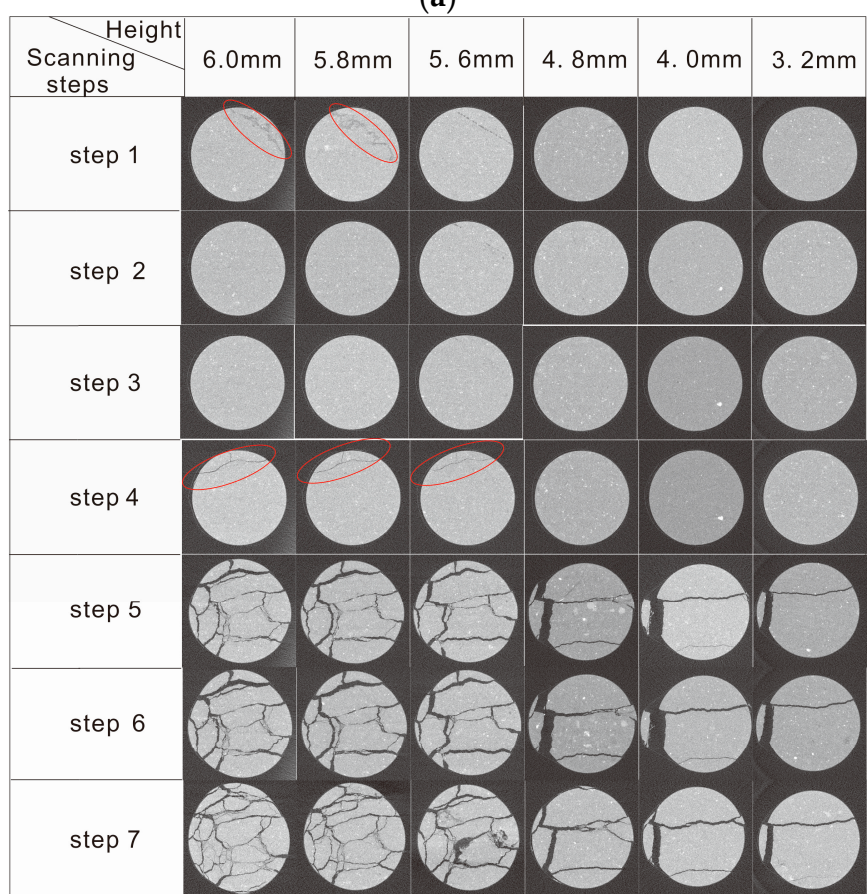

(b)

Figure 4. Scanning results of sample 3: (a) the stress-strain relationship and some CT images at $6 \mathrm{~mm}$ height corresponding to each scanning step; (b) some CT images at different scanning steps and sample heights. 


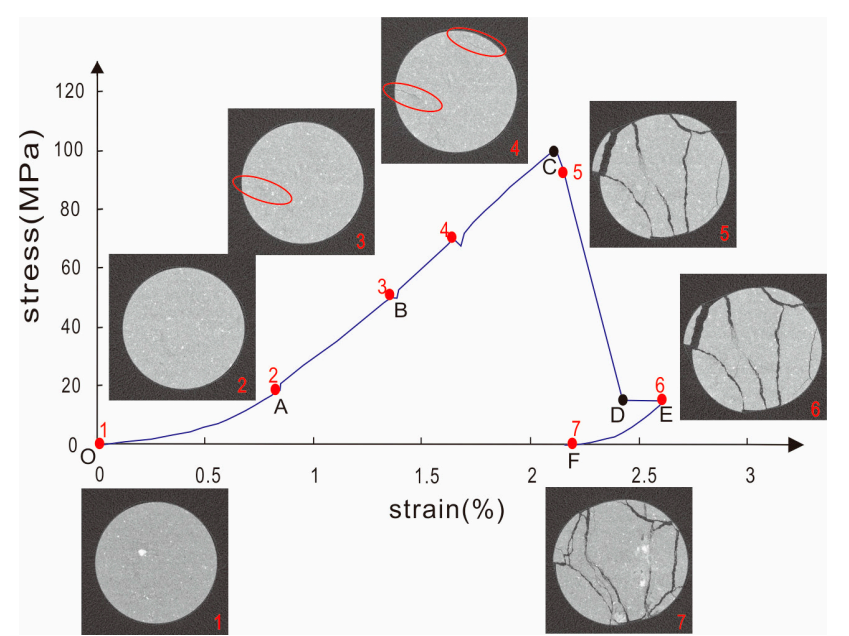

(a)

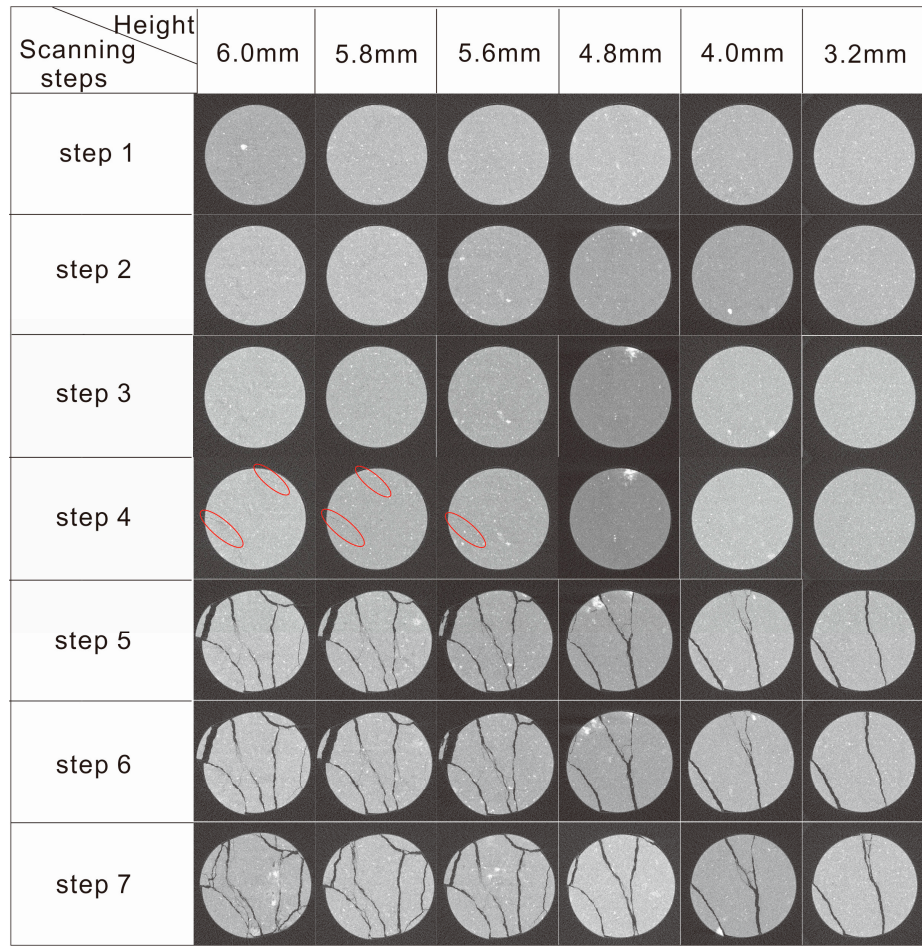

(b)

Figure 5. Scanning results of sample 4: (a) the stress-strain relationship and some CT images at $6 \mathrm{~mm}$ height corresponding to each scanning step; (b) some CT images at different scanning steps and sample heights.

\subsection{Three Dimensional (3-D) Reconstruction and Failure Mechanism}

The horizontal X-ray CT images reflect the density variation of cross sections, which lose the information of the vertical cracks. Software named VG Studio MAX 2.1 was used to reconstruct stereograms, from which the surface characteristics of the vertical cracks can be revealed. Some virtual slices can then be obtained from those stereograms in order to analyze the situation of the internal cracking. Five hundred CT images in the middle of samples (corresponding to height of 2-6 mm) at each scanning step were chosen for reconstruction. A cylindrical stereogram of approximately $4 \times 4 \mathrm{~mm}$ was obtained for each step. Here only the results of the failed samples were shown. Figure 6 shows the 3-D reconstruction and some slices of sample 3, Figure 7 shows the results of 3-D reconstruction and some slices of sample 4 . Those slices were selected using an aligned clipping box (the name of 
an operational tool in VG Studio), from which the internal slices at the specified coordinates in the reconstructed stereograms can be obtained. There are three slices in each direction.

The characteristics of the surface cracks at different view directions in sample 3 are shown in Figure 6a. The phenomenon of spalling at the left edge is most obvious from the front view, the surface damage is serious at the right view and the left view, and cracks are much complex at the top by comparing the top view and the bottom view. As shown in Figure 6b, the internal cracks at different slices can be analyzed. There are many inclined and short vertical cracks occurring in the top quarter of the sample where the shale is seriously destructed. A main slightly tilted crack occurs in the bottom three quarters of the sample. There is also a short inclined crack at the bottom edge.

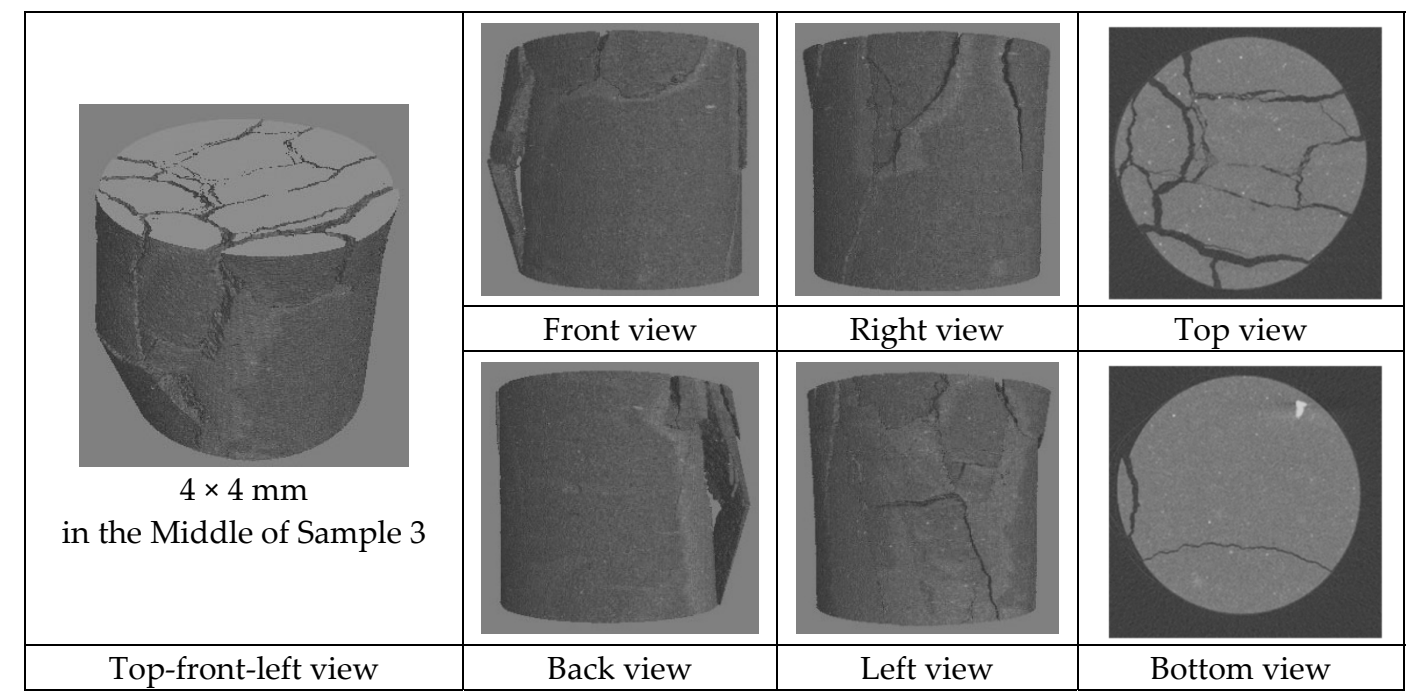

(a)

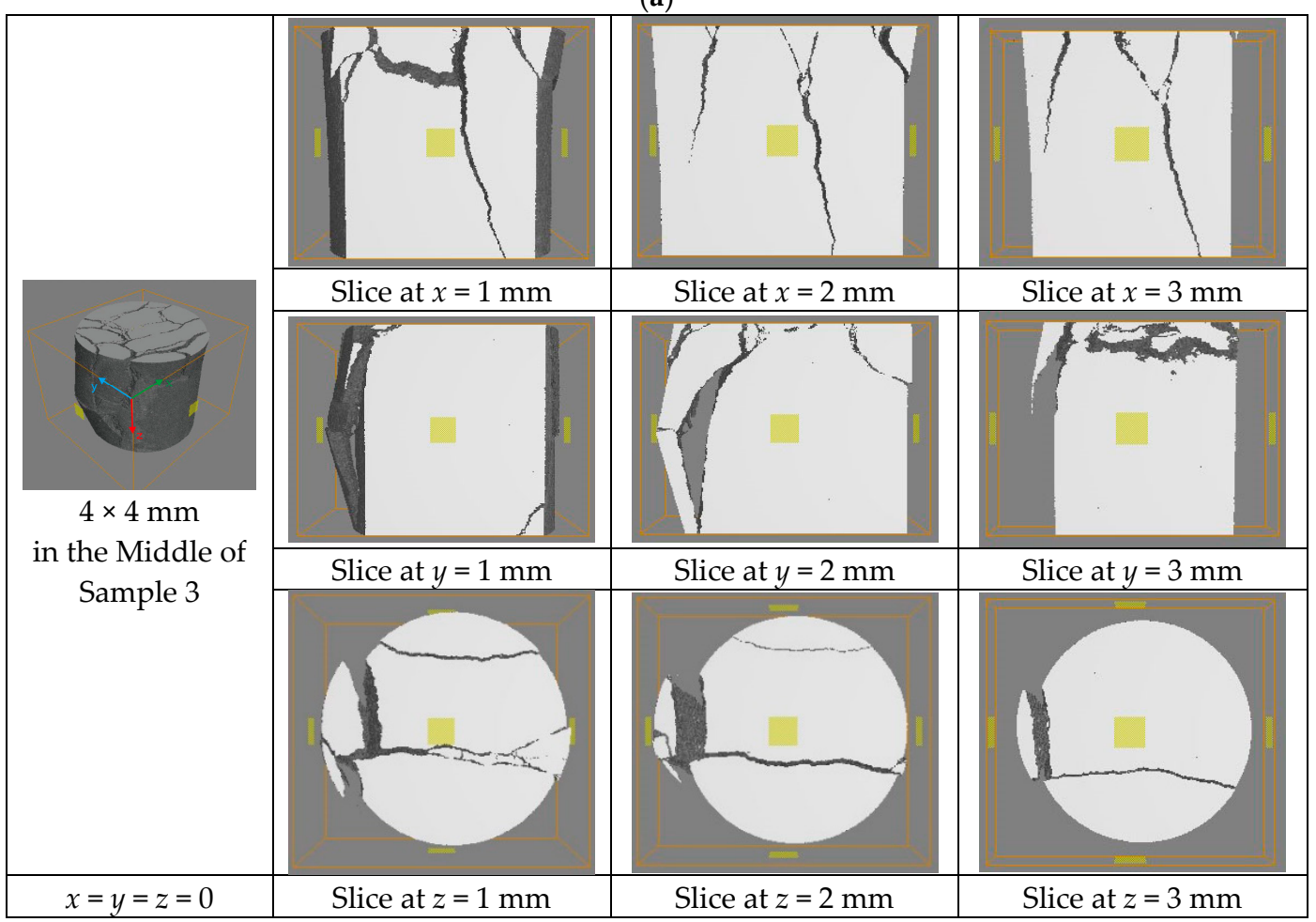

(b)

Figure 6. Results of the 3-D reconstruction of sample 3 after failure: (a) the stereograms at different directions of view; (b) virtual slices and their locations in the stereogram. 


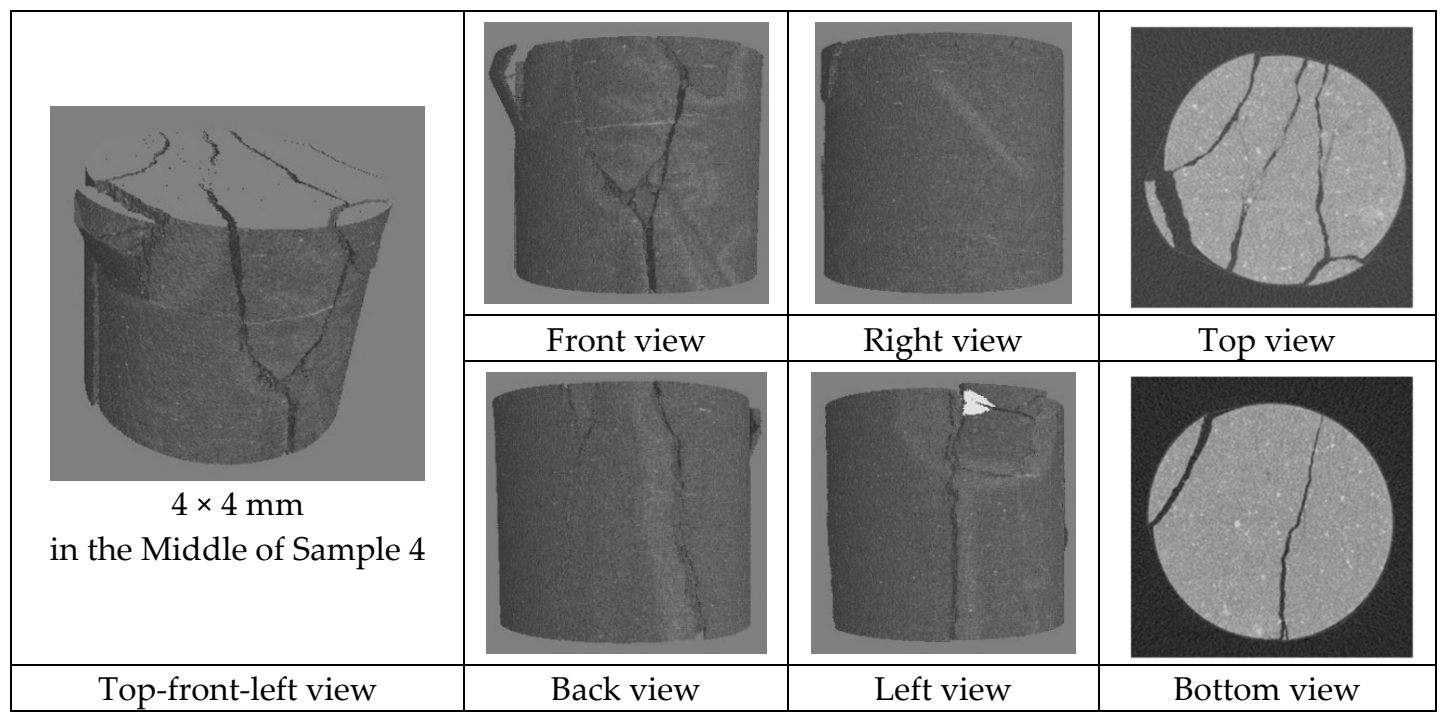

(a)

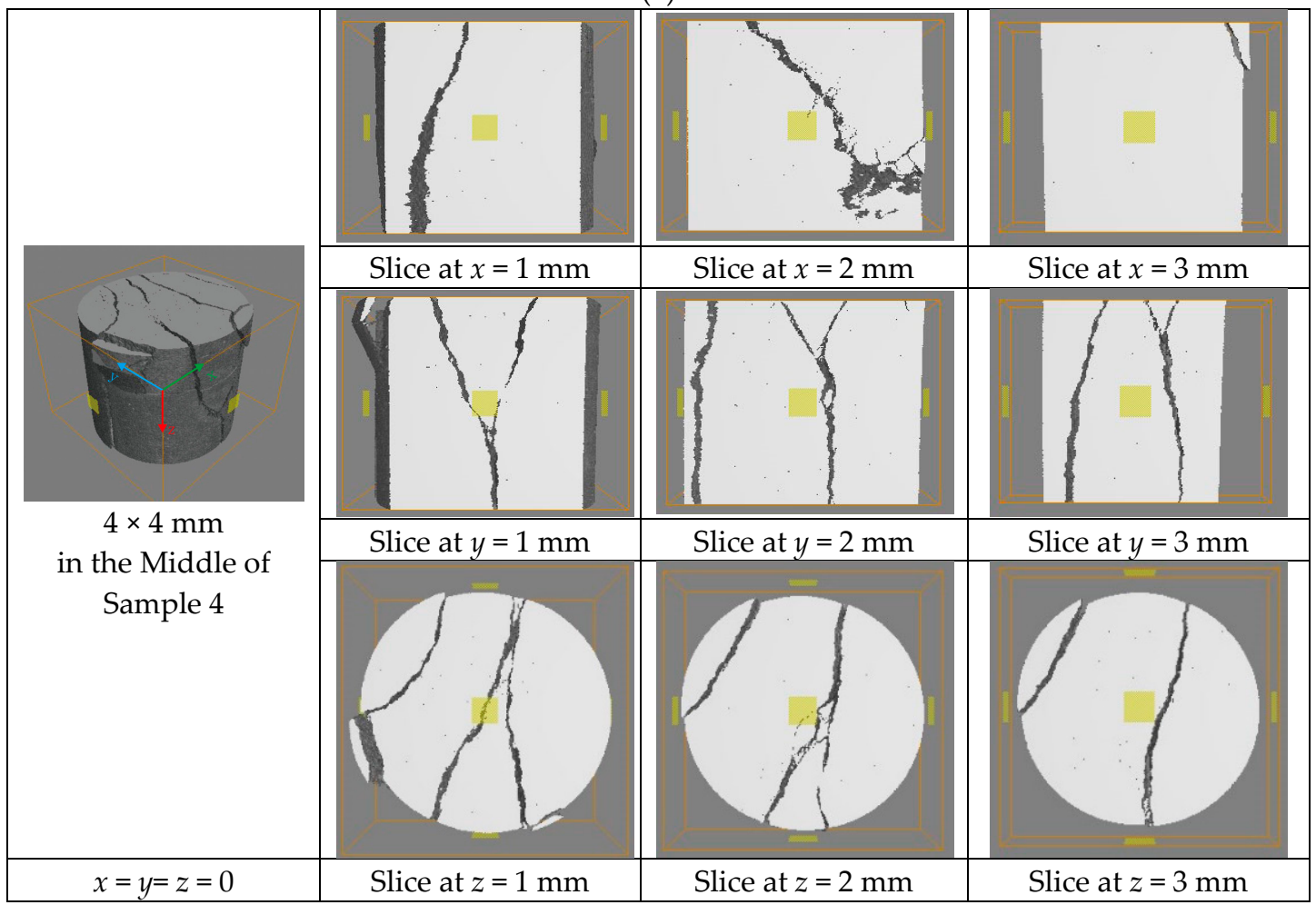

(b)

Figure 7. Results of the 3-D reconstruction of sample 4 after failure: (a) the stereograms at different directions of view; (b) virtual slices and their locations at the stereogram.

The characteristics of surface cracks at different view directions of sample 4 were shown in Figure 7a. There is an obvious " $Y$ "-shaped crack in the front view, and small spalling at the top edge can also be observed. A vertical crack exists from the left view and a slightly tilted crack exists from the back view. As shown in Figure 7b, the internal cracks can be analyzed. There are four main cracks in sample 4 . One of them is a single inclined crack at the left part, which has a $15^{\circ}$ angle to the vertical direction. While the other three have spatial syntagmatic relations, two inclined cracks in opposing directions occur at the top, then they slowly close into each other. The two inclined cracks finally intersect into an oblique line. Lastly, a vertical crack along the intersected line to the bottom of the sample forms the " $\mathrm{Y}^{\prime}$ pattern of failure [30]. 
Combining the characteristics of cracks in the stereograms' surfaces with the internal slices, the failure mechanism of shale can be analyzed. Vertical and the inclined cracks both occurred in two samples. These cracks constitute quite complex crack networks, especially at the upper edge of the samples. However, the spatial relations of those cracks show some differences between samples 3 and 4 . On the one hand, there is a main slightly tilted crack in sample 3, however there is the " $Y$ " failure pattern in sample 4. According to the previous research results, when the fractured plane is perpendicular to the bedding plane, it is easy to produce tensile cracks; however when the fractured plane has an angle of about $45^{\circ}$ with the bedding plane, tensile and shear cracks often occur concomitantly [31]. Thus, a main slightly tilted crack in sample 3 indicates that tension destruction caused by the axial splitting is the main mechanism. The " $Y$ " failure pattern in sample 4 indicates that the failure mechanism is tension-shear composite destruction. On the other hand, the shape change of the pyrite inclusions band is powerful evidence for the mechanism of sample 4. As shown in Figure 8, the original pyrite inclusions band was horizontal, but this band was staggered by two inclined cracks after the test. The displacement of this stagger is approximately $0.2 \mathrm{~mm}$ and confirms the existence of shear rupture in sample 4 . There may also be shear rupture in sample 3 but evidence is lacking. Thus, the mechanism of sample 3 is mainly tension destruction while in sample 4 it is comprehensive tension-shear destruction.

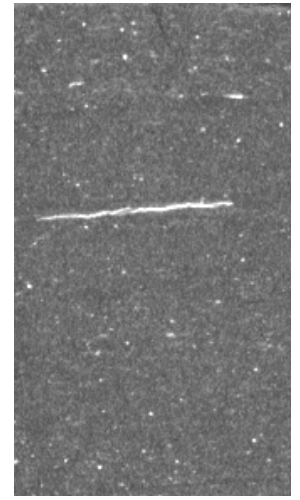

(a)

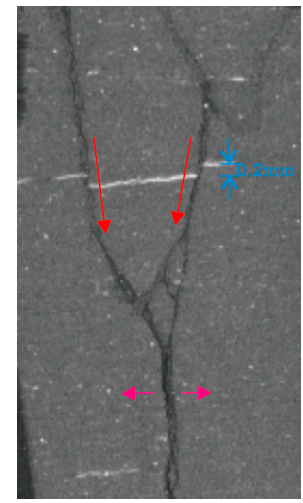

(b)

Figure 8. The morphology of pyrite inclusions band in sample 4: (a) the morphology before test; (b) the morphology after test.

\section{Discussion}

The characteristics of the stress-strain relationship are the important basis for analyzing the rock deformation-failure system [32]. Since the 1970s, Brady et al. [33], Jaeger and Cook [34] and Brace and Kohlstedt [35] have discussed the full process of rock damage behavior. Ge et al. [36] summarized that the shape of curves is related to the changing of physical parameters. Pan et al. [37] and Luo et al. [38] researched that the stress-strain relationship corresponds with AE events. However, that research cannot reflect the real propagation of the internal cracks by the measurement of indirect physical quantities. The results of X-ray micro-CT in this study intuitively reflect the evolution process of cracks. Some low-density regions in the CT images exist and disappear, some small cracks appear at the upper edge of the CT images at the pre-peak scanning steps and some secondary cracks are produced in the CT images after unloading. Those phenomena verify the correctness of the pre-peak stages and enrich the post-peak failure characteristic of shale. The evolution process of cracks corresponds with stress-strain curves.

The testing results of samples 3 and 4 share a similar shape of the stress-strain relationship. The progressive failure process can be divided into six stages according to the stress-strain relationship and cracking development, but the values of peak strength and elastic modulus of sample 4 are greater than sample 3 , in comparison to the testing results from the mesoscopic point of view by analyzing 
the CT scanning images (Figures $4 \mathrm{~b}$ and $5 \mathrm{~b}$ ). Some light-colored minerals are scattered in the scanned samples (samples 3 and 4). Small cracks occurred at the upper edge of the specimens before peak and many more cracks occurred after failure, as shown in the CT images of the both scanned samples. However, the distributions of the initial defects are different: there is a pyrite inclusions band in sample 4 whereas low-density regions are present in sample 3 . The differences in initial defects can influence the characteristics of initial cracks. Two initial cracks occurred at the upper edge in sample 4 while only one initial crack occurred in sample 3. Thus, the differences of the initial cracking really influence the failure patterns of the two shale samples. The finial cracks in the CT images of sample 3 are more complex on the upper side. By contrast, the cracks are simpler at the bottom when compared with sample 4, because there is a crack at the bottom of sample 3, as opposed to two slightly wider cracks in sample 4 . The spatial relations of cracks are different, although there are the vertical and inclined cracks occurring in both samples. There is a main slightly tilted crack in sample 3 , while the " $Y$ " failure pattern in sample 4 corresponds to the morphology of cracks in the stereograms' surfaces and the internal slices. The meso-characteristics of the two samples mark the differences in the form of the crack initiation, which directly leads to the differences in the form of the final crack networks and the macroscopic mechanical behavior. The failure mechanisms of the two samples are different in nature. They are mainly single tension destruction and comprehensive tension-shear destruction, respectively.

\section{Conclusions}

A new test system with high resolution and loading capacity was used to conduct indoor real-time tests. Compact and high-strength Longmaxi shale was first studied under in-situ uniaxial compression. High-resolution CT images at different scanning steps were obtained to analyze the shale progressive failure. Then stereograms were constructed and some slices were selected to observe the internal cracks and explain the failure mechanism of the shale. The main conclusions obtained in this study are as follows:

1. Through the analysis of stress-strain relationship and consecutive CT images obtained during the loading process, the deformation and failure process of shale can be divided into six stages. They are initial compression stage, linear elastic deformation stage, crack initiation and growth stage, strain-softening stage, residual deformation stage and unloading stage.

2. Compaction of the low-density area and the appearance of small cracks could be observed through the CT images before peak stress during the loading, as well as the emergence of numerous cracks after failure and the dual effect of unloading were discovered. These phenomena can not only verify the pre-peak evolution process of cracks, but also enrich the post-peak failure characteristics of shale.

3. The different initial meso-characteristics of the shale samples really can make the differences for the crack initiation, which directly leads to the differences between the macroscopic mechanical behavior and the final crack networks. A main slightly tilted crack and a " $Y$ " failure pattern crack were respectively observed in shale samples. The failure mechanisms were judged by the failure pattern of cracks and the staggering of the pyrite inclusions band. It is concluded that the failure mechanisms of shale can be different in nature. They include mainly tension destruction and comprehensive tension-shear destruction.

4. This real-time CT scan of shale samples under uniaxial loading conditions reveals the characteristics of the internal cracks and the gradual evolution of the cracking during the loading process. The progressive failure process can be used for correctly understanding the progressive failure and mechanism of shale. Then it can make a meaningful contribution to fracturing engineering and discover more unconventional energy sources. 
Acknowledgments: The authors would like to thank the Editor and the anonymous reviewers for their helpful and constructive comments. This work is supported by the Strategic Priority Research Program of the Chinese Academy of Sciences (Grant No. XDB10030301) and the National Natural Science Foundation of China (Grant No. 41227901).

Author Contributions: Each author has made contribution to the present paper. Xiao Li and Yongting Duan conceived and designed the experiments; Runqing Zhou performed the experiments; Yongting Duan processed and analyzed the experimental data; Shouding Li provided the experimental support. General supervision was provided by Xiao Li. All authors have read and approved the final manuscript.

Conflicts of Interest: The authors declare no conflict of interest.

\section{References}

1. Yuan, W.N.; Pan, Z.J.; Li, X.; Yang, Y.X.; Zhao, C.; Connell, L.D.; Li, S.D.; He, J.M. Experimental study and modelling of methane adsorption and diffusion in shale. Fuel 2014, 117, 509-519. [CrossRef]

2. Wang, Q.; Li, R.R. Natural gas from shale formation: A research profile. Renew. Sustain. Energy Rev. 2016, 57, 1-6. [CrossRef]

3. Hughes, J.D. Energy: A reality check on the shale revolution. Nature 2013, 494, 307-315. [CrossRef] [PubMed]

4. Boersma, T.; Johnson, C. The shale gas revolution: US and EU policy and research agendas. Rev. Policy Res. 2012, 29, 570-576. [CrossRef]

5. Yang, J.; Fu, Y.Q.; Chen, H.F.; Zeng, L.; Li, J.H. Rock mechanical characteristics of shale reservoirs. Nat. Gas 2012, 32, 12-16.

6. Li, Q.H.; Chen, M.; Jin, Y.; Zhou, Y. Rock Mechanical Properties of Shale Gas Reservoir and Their Influences on Hydraulic Fracture. In Proceedings of the 2013 International Petroleum Technology Conference, Beijing, China, 26-28 March 2013.

7. Roshan, H.; Sarmadivaleh, M.; Iglauer, S. Shale fracture surface area measured by tracking exchangeable cations. J. Pet. Sci. Eng. 2016, 138, 97-103. [CrossRef]

8. Cao, G.Z.; Qiang, Y.; Li, F. Real-Time Observations of Fracturing Processes of Brittle Rock in Compression by X-ray Computed Tomography. Adv. Mater. Res. 2011, 361, 171-178. [CrossRef]

9. Patricia, D.; Clive, M.; Jeremy, S. Velocity anisotropy and attenuation of shale in under- and over pressured conditions. Geophys. Prospect. 2002, 50, 487-503.

10. Dewhurst, D.N.; Siggins, A.F.; Sarout, J.; Raven, M.D.; Nordgårdbolås, H.M. Geomechanical and ultrasonic characterization of a Norwegian Sea shale. Geophysics 2011, 76, 101-111. [CrossRef]

11. Yan, C.L.; Gen, D.J.; Hu, L.B.; Chen, Z.J.; Yan, X.J.; Lin, H.; Tan, Q.; Yu, B.H. Brittle failure of shale under uniaxial compression. Arab. J. Geosci. 2015, 8, 2467-2475.

12. Amann, F.; Button, E.A.; Evans, K.F.; Gischig, V.S.; Blümel, M. Experimental Study of the Brittle Behavior of Clay shale in Rapid Unconfined Compression. Rock Mech. Rock Eng. 2011, 44, 415-430. [CrossRef]

13. Qiao, L.; Ranjith, P.G.; Long, X.P.; Kang, Y.; Huang, M. Effects of coring directions on the mechanical properties of Chinese shale. Arab. J. Geosci. 2015, 8, 10289-10299.

14. Niandou, H.; Shao, J.F.; Henry, J.P.; Fourmaintraux, D. Laboratory Investigation of the Behavior of Tournemire Shale. Int. J. Rock Mech. Min. Sci. 1997, 34, 3-16. [CrossRef]

15. Li, Q.H.; Chen, M.; Jin, Y.; Wang, F.P.; Hou, B.; Zhang, B. Indoor Evaluation Method for Shale Brittleness and Improvement. Rock Mech. Rock Eng. 2012, 31, 1680-1685.

16. Jia, C.G.; Lu, H.J.; Guo, Y.T.; Yang, C.H.; Xu, J.B.; Wang, L. Research on mechanical behaviors and failure modes of layer shale. Rock Soil Mech. 2013, 34, 57-61.

17. Hou, Z.K.; Yang, C.H.; Guo, Y.T.; Zhang, B.P.; Wei, Y.L.; Heng, S.; Wang, L. Experimental study on anisotropic properties of Longmaxi formation shale under uniaxial compression. Rock Soil Mech. 2015, 36, 2541-2550.

18. Zhang, Y.Z.; Liu, J.X.; Mao, H.J.; Huo, L.; Hou, Z.K. Anisotropic Experimental Study on Mechanical Properties of Shale under Uniaxial Compression. Met. Mine 2015, 12, 33-40.

19. Ma, Y.; Pan, Z.J.; Zhong, N.N.; Connell, L.D.; Down, D.I.; Lin, W.L.; Zhang, Y. Experimental study of anisotropic gas permeability and its relationship with fracture structure of Longmaxi Shale, Sichuan Basin, China. Fuel 2016, 180, 106-115. [CrossRef]

20. Zou, Y.S.; Zhang, S.C.; Zhou, T.; Zhou, X.; Guo, T.K. Experimental Investigation into Hydraulic Fracture Network Propagation in Gas Shale Using CT Scanning Technology. Rock Mech. Rock Eng. 2016, 49, $33-45$. 
21. Hall, S.A.; Bornert, M.; Desrues, J.; Pannier, Y.; Lenoir, N.; Viggiani, G.; Bésuelle, P. Discrete and continuum analysis of localized deformation in sand using $\mathrm{X}$-ray $\mu \mathrm{CT}$ and volumetric digital image correlation. Géotechnique 2010, 60, 315-322. [CrossRef]

22. Higo, Y.; Oka, F.; Kimoto, S.; Sanagawa, T.; Matsushima, Y. Study of Strain Localization and Microstructural Changes in Partially Saturated Sand during Triaxial Tests using Micro-focus X-ray CT. Soils Found. 2011, 1, 95-111. [CrossRef]

23. Andò, E.; Hall, S.A.; Viggiani, G.; Desrues, J.; Bésuelle, P. Experimental micromechanics: Grain-scale observation of sand deformation. Géotech. Lett. 2012, 2, 107-112. [CrossRef]

24. Andò, E.; Hall, S.A.; Viggiani, G.; Desrues, J.; Bésuelle, P. Grain-scale experimental investigation of localized deformation in sand: A discrete particle tracking approach. Acta Geotech. 2012, 7, 1-13. [CrossRef]

25. Fonseca, J.; Bésuelle, P.; Viggiani, G. Micro-mechanisms of inelastic deformation in sandstones: An insight using x-ray micro-tomography. Géotech. Lett. 2013, 3, 78-83. [CrossRef]

26. Higo, Y.; Oka, F.; Sato, T.; Matsushima, Y.; Kimoto, S. Investigation of localized deformation in partially saturated sand under triaxial compression using micro-focus X-ray CT with digital image correlation. Soils Found. 2013, 53, 181-198. [CrossRef]

27. Chen, W.X.; He, X.Q.; Liu, M.J.; Mitri, H.; Wang, Q. Meso- and macro-behaviour of coal rock: Observations and constitutive model development. Int. J. Min. Reclam. Environ. 2014, 30, 13-24. [CrossRef]

28. Hou, Z.K.; Yang, C.H.; Wei, X.; Wang, L.; Wei, Y.L.; Xu, F.; Wang, H. Experimental study on the brittle characteristics of Longmaxi formation shale. J. China Coal Soc. 2016, 41, 1188-1196.

29. Bésuelle, P.; Viggiani, G.; Lenoir, N.; Desrues, J.; Bornert, M. X-ray Micro CT for Studying Strain Localization in Clay Rocks under Triaxial Compression. In Proceedings of the Geox 2006: Advance in X-ray Tomography for Geomaterials, Kyoto, Japan, 23-24 October 2006; pp. 35-53.

30. You, M.Q. Fracture of Rock Specimen and Decrement of Bearing Capacity in Uniaxial Compression. Rock Mech. Eng. 1998, 17, 292-296.

31. Yin, S.; Ding, W.L.; Sun, Y.X.; Wang, X.H.; Zhang, M.; Zhang, N.J. Shale Uniaxial Compressive Failure Property and the Affecting Factors of UCS. Earth Sci. Front. 2016, 23, 75-95.

32. Xiao, S.F. The Deformation and Failure Mechanism of Different Rocks and Their Acoustic Characteristics. J. Changchun Univ. Earth Sci. 1980, 3, 53-60.

33. Brady, B.T.; Duvall, W.I.; Horino, F.G. An experimental determination of the true uniaxial stress-strain behavior of brittle rock. Rock Mech. Rock Eng. 1973, 5, 107-120. [CrossRef]

34. Jaeger, J.C.; Cook, N.G.W. Rock Mechanics. In Fundamentals of Rock Mechanics; Chapman and Hall: London, UK, 1976.

35. Brace, W.F.; Kohlstedt, D.L. Limits on Lithospheric Stress Imposed by Laboratory Experiments. J. Geophys. Res. Atmos. 1980, 85, 6248-6252. [CrossRef]

36. Ge, H.P.; Sun, Y.; Zhu, W.B.; Guo, J.C.; Liu, D.L.; Chen, X.Y.; Wang, F.; Wen, S.H. Experiment on the Fracture Behavior in Rocks. Geol. J. China Univ. 2004, 10, 290-296.

37. Pan, Y.; Tang, S.H.; Wen, X.; Tang, H.Y. Study on the Acoustic Emission during Rock Damage Process under the Condition of Uniaxial Compression. Min. Res. Dev. 2011, 31, 56-59.

38. Luo, F.Y.; Luo, F.L.; Deng, F.; Liu, G.J.; Yang, H.; Liu, D. Acoustic Emission Characteristics and Damage Evolution of Sandstone under Uniaxial Compression Condition. China Tungsten Ind. 2014, 6, 7-10.

(C) 2017 by the authors. Licensee MDPI, Basel, Switzerland. This article is an open access article distributed under the terms and conditions of the Creative Commons Attribution (CC BY) license (http://creativecommons.org/licenses/by/4.0/). 